\title{
AURORA COMO PROYECTO EDUCATIVO
}

\author{
Dawn as an educational Project \\ Mariano Rodríguez \\ Universidad Complutense de Madrid
}

RESUMEN: Las reflexiones educacionales de Aurora se compaginan bien con la general filosofía nietzscheana de la educación, al liberar al individuo de la moralidad de la costumbre, porque solo así será capaz de llegar a ser el que es. Demandará Nietzsche una educación que enseñe a soportar la soledad como camino hasta uno mismo y la propia creatividad. Se subraya, también, su crítica de las instituciones educativas de la época, para acabar tratando el problema filosófico central de la educación, el planteado por el nuevo sujeto pulsional nietzscheano.

Palabras clave: Individuo - moralidad de la costumbre - soledad - sujeto

ABSTRACT: This article interprets Nietzsche's position on education, from a philosophy that is related to the ancient tradition of philosophy as a way of life and art of existence. It is elaborated from an idea that starts from the singularity as an assumption at the same time as purpose. It analyzes the idea of a master who wants disciples to break with him, to finally arrive to Nietzsche himself as a teacher of humanity. Finally, to have Nietzsche as a master is to act on the possibility of paradox, it is to open oneself to the multiplicity of possible worlds, and not to surrender anything to possession.

Keywords: Individual - morality - of custom - solitude - subject 


\section{NiETZSCHE, LA EDUCACIÓN Y AURORA}

Al problema de la educación le corresponde un papel importante en la obra de Nietzsche en su totalidad, desde los escritos tempranos especialmente dedicados al mismo hasta las observaciones y reflexiones, poco organizadas pero abundantes, que encontramos esparcidas por los escritos tanto publicados como póstumos. Si pensamos que la actividad filosofante sería, en buena medida, una actividad educacional, creeremos justificada la tesis de que «hay un sentido perfectamente adecuado en el que la completa empresa filosófica de Nietzsche es educativa» (Cooper 2010: 22). Cuando aún ejercía la docencia en Basilea, él mismo lo iba a considerar así: "Yo también no conozco meta más elevada para mí mismo que la de llegar a ser algún día "educador" en sentido grande: solo que estoy muy lejos de esta meta» (CO II: 465) ${ }^{1}$. Habría sido entonces el fin supremo de Nietzsche el de convertirse en educador. Pero en educador en sentido grande, y no en el de mero profesor de una institución de enseñanza. Lo que sería lo mismo que decir educador en el sentido de filósofo, o educador de la humanidad.

Por otra parte, y coincidiendo, precisamente, con su abandono de la actividad académica, en los dos años que van de 1876 a 1878 va a consumarse, como se sabe, una ruptura significativa del filósofo con toda su trayectoria anterior, en especial con Wagner y los wagnerianos, ruptura que culminará en la publicación de Humano, demasiado humano. Entramos con esta obra en su periodo intermedio, el de los escritos del espíritu libre. Y Aurora va a aportar novedades, o cuando menos matizaciones muy relevantes, a la filosofía de este periodo, tal y como se inaugura en la obra anterior. Pero por otro lado hay que sostener que la filosofía educacional de Nietzsche, ya desde los escritos tempranos que más la desarrollaron específicamente (Sobre el futuro de nuestras instituciones educativas, Sobre la utilidad y el perjuicio de la historia para la vida y Schopenhauer como educador), guardará una notable coherencia hasta el final de su vida lúcida. Lo cual nos podría recordar la bien establecida idea de una línea más o menos coherente en toda la obra nietzscheana, a despecho y por debajo de sus reconocidos giros y etapas (cfr. Sánchez Meca 2018: 153-162). Una relativa continuidad esta, muy probablemente, basada en la originaria adopción del modelo griego, y más en concreto, en el descubrimiento nietzscheano de lo dionisíaco, reconocible también en la reflexión educativa del filósofo (Dumonteil 2015).

Nietzsche procurará ajustar sus frecuentes incursiones en nuestro tema a los diferentes marcos filosóficos que su pensamiento en general va a ir

1 De la carta 362, a Emma Guerrieri-Gonzaga en Florencia, desde Basilea, 10 de mayo de 1874. 
atravesando. En el caso del periodo en torno a El nacimiento de la tragedia, esta necesaria tarea de encaje resultará más ardua. Reflexionando el filósofo, entonces, sobre «la finalidad de la educación (Erziehung)» (FP I 1416 [1]), el eco de Schopenhauer determinará que la viabilidad conceptual de la así denominada «educación para el conocimiento trágico» no sea fácil de despejar. Por lo menos en la medida en que hay que partir en ella de la negación tanto de la libertad de la voluntad como de la libertad del pensamiento. Esta primera vez el rechazo de las dos libertades viene dictado por el convencimiento metafísico de que nosotros los humanos seríamos tan solo «apariencia». Y resulta que de esto se seguiría la negación de la misma posibilidad de la educación. La salida de Nietzsche bien pudo consistir, por aquella época, en la decisión de mantenerse firme en una suerte de incómodo divorcio de teoría y práctica:

Una educación para el conocimiento trágico presupone, por tanto, una capacidad definida del carácter, una libre decisión de elección, etc. - en la práctica, pero teóricamente niega esto mismo y pone este problema inmediatamente en el vértice de la educación. Nosotros nos comportaremos siempre como nosotros somos y nunca como nosotros debemos ser. (FP I 1416 [3]).

Frente a esta educación para el genio del primer gran momento nietzscheano: «Educación. Representaciones ilusorias» (FP I 1426 [6]), el marco propio de las obras del espíritu libre, en cambio, ofrecerá oportunidades más claras de una «fundamentación» no ilusoria del fenómeno educativo ${ }^{2}$. Veamos si no la misma «definición» inicial del espíritu libre, con la intención de recordarla cuando emerja el nuevo sentido de la educación en Aurora: «Se llama espíritu libre a quien piensa de manera distinta a lo que se esperaría atendiendo a sus orígenes, su entorno, su posición social y su profesión, o a las opiniones dominantes de la época. Él es la excepción, los espíritus sometidos la regla» (HH I, 225: 170). El planteamiento mismo que abre la etapa intermedia cuadrará, de una forma más natural que la metafísica artística, con el radical individualismo característico de la filosofía nietzscheana de la educación desde el principio hasta el final. Veamos si no un importante fragmento póstumo de otoño de 1887, que consigna lo esencial de la crítica que Nietzsche dirige invariablemente a la educación establecida. Por mucho que reconozca el filósofo lo justificado de su proceder desde un cierto punto

2 Bien es cierto que de una manera nada más que relativa, puesto que, como se verá al final de este trabajo, en Aurora también acechan problemas filosóficos de envergadura, sobre todo uno semejante en relación con la noción de sujeto y la libertad de la voluntad. 
de vista «económico», encontramos aquí la denuncia de la índole igualadora, homogeneizadora, de una educación centrada en sofocar la diferencia:

Educación [Erziehung]: esencialmente el medio de arruinar la excepción, de desviarla, seducirla, enfermarla, en favor de la regla. Es duro: pero considerado desde un punto de vista económico, perfectamente razonable. Por lo menos durante ese largo tiempo_ — — Formación [Bildung]: esencialmente el medio de dirigir el gusto contra la excepción en favor de lo mediocre. (FP IV 2779 [139]).

El espíritu libre se rebela contra todo tipo de autoridad, mientras que el espíritu sometido reclama obediencia incondicional al que la detenta. El espíritu libre se libera de la tradición, y de las creencias y maneras de sentir y de pensar habituales, mientras que el espíritu servil sigue siendo víctima voluntaria de los principios intelectuales tradicionales, sujetándose a las normas usuales de conducta. Como a lo que aspiran es a uniformizar toda organización social, los espíritus serviles adoptarán sin ningún problema las convicciones de su época, haciendo de ellas una verdadera segunda naturaleza para sí mismos, sin entrar jamás en el cuestionamiento de las razones por las que se las habría que incorporar (Marton 2021: 46). Si bien es cierto que la llamada nietzscheana a prescindir de toda creencia en el sentido fuerte del término, esto es, como creencia metafísica, religiosa o moral, para así dejar de ser mandados por otros, y pasar a ser por fin los dueños de nuestra propia vida, no la encontraremos en su forma más contundente hasta el quinto libro de La gaya ciencia (cfr. GC 347), ya en la primera parte de Humano, demasiado humano habíamos podido ver a nuestro filósofo muy cierto del sentido nivelador de la educación institucionalizada.

«La educación cívica, política o religiosa implica un proceso que tiene como meta hacer a los que son educados semejantes a aquellos que los educan. El principio de toda organización gregaria consiste entonces en eliminar las diferencias y en suprimir las singularidades. En este sentido Nietzsche afirma:» (Marton 2021: 46) «Todos los Estados y organizaciones sociales: las clases, el matrimonio, la educación, el derecho, todo ello tiene su fuerza y duración únicamente en la fe que los espíritus sometidos le prestan-por tanto, en la ausencia de razones, o por lo menos en el rechazo a ponerlas en cuestión» (HH I 227: 171). Subrayar el hecho de que la filosofía de la etapa intermedia tendría una evidente capacidad de adaptarse al núcleo más vivo de las reflexiones educacionales que recorren toda la obra del filósofo, en realidad significa compartir sin reservas la tesis de Ansell-Pearson \& Bamford (2021: 22), según la cual, con Humano, demasiado humano, Nietzsche daría comienzo a un importante proyecto educativo de carácter filosófico, centrado 
en la reforma de la mente humana. Lo que queremos defender nosotros es que Aurora sería la siguiente etapa de ese proyecto.

Es importante no pasar por alto el giro concreto que Aurora imprimirá a la filosofía del espíritu libre, puesto que se va a reflejar en sus reflexiones educativas. Tendríamos para empezar la crítica de los prejuicios morales, o sea, aquello que supone el comienzo o el punto de partida de la capital empresa nietzscheana de la transvaloración, proseguida y precisada en los ulteriores escritos de madurez. Después, en Aurora encontramos en acción a la gran pasión con la que Nietzsche se entrega a la tarea del conocimiento. Pero esta pasión del conocimiento, y aquella crítica de la moral occidental, vendrían las dos en Aurora cogidas de la mano, incluso se podría afirmar que serían como las dos caras de una misma moneda. A decir verdad, lo que nos regala Aurora es una nueva imagen y un nuevo ideal del espíritu libre, toda una forma de vida poseída por la seriedad de la pasión del conocimiento. Ahora bien, lo que Nietzsche expone en este gran libro suyo es su propia experiencia formativa o de subjetivación, en cuanto experiencia de la escritura. Porque es escribiendo como nuestro filósofo habría encontrado la clave de sí mismo. Por la escritura, Nietzsche habría conseguido elevar su experiencia vital a totalidad estética, y es por tanto escribiendo como él llega a ser, cada vez en mayor medida, aquel que es (Brusotti 1997: 200-203). Sobre este decisivo extremo volveremos en la conclusión de este trabajo.

Se ha podido establecer justificadamente que, si Aurora busca cuestionar la moralidad de la costumbre, pero para motivar así nuestro interés crítico en lo propiamente ético (Ansell-Pearson \& Bamford 2021: 2), entonces este libro de Nietzsche nos acabaría lanzando a una investigación sin trabas de uno mismo y de su mundo. Esta investigación incesante constituye en sí misma una tarea ética porque nos va a enseñar maneras inéditas de articular la subjetividad, a partir del descubrimiento de nuestra constitución pulsional, junto con el análisis de las posibilidades de cultivarla o de auto-cultivarnos.

Nietzsche iba a ser consciente, a lo largo del año 1880, de que algo importante había cambiado en él, y por tanto en su trabajo filosófico. Los conocimientos a que llegaba ese año eran precisos, capaces de quitar el velo que cubre a las cosas haciéndolas comunicables. A lo oculto quería entonces forzarlo el filósofo a arrojar la máscara lejos de sí (Görner 2000: 215). Por eso es Aurora mucho más radical que Humano, demasiado humano, pues no en vano contiene ya en esbozo el proyecto de la transvaloración de todos los valores. El mismo Görner (2000: 217) acierta al conectar esto con la pedagogía de la soledad que Nietzsche pondría en marcha en la obra. Y es que el proyecto científico del mundo se uniría en Aurora, de forma inaudita, al proyecto de hacer del hombre un poeta de sí mismo. Pero en la filosofía nietzscheana de la 
educación se trataría justo de eso, de que «nosotros queremos llegar a ser los que somos» (Görner 2000: 227).

\section{El SENTIDO DE LA EDUCACIÓN EN AURORA}

En el apartado de los resultados positivos de la presente investigación, descubrimos en primer lugar que sería en el individuo, efectivamente, donde se resuelve todo el sentido de la educación en Aurora. Algo que sin duda iría en el mismo sentido general de la filosofía nietzscheana de la educación. Dumonteil (2015) sostiene que el modelo absoluto de las reflexiones nietzscheanas sobre el fenómeno educativo fue siempre el de la Antigüedad Grecorromana, verdadera escuela primordial de Occidente. Es cierto que, en Aurora, el lugar de los filósofos «de la época trágica de los griegos» lo van a ocupar los del mundo helenístico. Epicteto, pero también Epicuro, sin perder de vista a los cínicos, y todo ello con un bajo continuo decididamente escéptico. Pero, en cualquier caso, sería desde la cultura antigua como se le hace posible a Nietzsche la crítica radical de la educación de su presente. Semejante crítica surgirá con coherencia desde la previa asunción, como principio educativo rector, del lema que daría expresión al imperativo de Píndaro llega a ser el que eres.

Asimismo, a lo largo de su obra, el filósofo entiende la educación como un proceso que habrá de favorecer la realización de los grandes individuos de acuerdo con su naturaleza. Por eso, la fórmula prescriptiva de Píndaro «Llega a ser el que eres» aparece no sólo en la obra de Nietzsche sobre Diógenes Laercio mientras es estudiante, sino también en Así habló Zaratustra y en La gaya ciencia. La exhortación de Schopenhauer educador «iSé tú mismo!» subraya así el hecho de que llegar a ser quien se es implica, de la parte del individuo, una liberación de las influencias externas. Estos factores nefastos para el desarrollo del individuo seguirán siendo los mismos en las obras posteriores del pensador: el egoísmo estatal, la economía, la mala filosofía, la ciencia y el arte decadentes (Dumonteil 2015: 140).

En el medio de este panorama general, Aurora se distinguirá al hacernos reconocer la necesidad de conciliar este imperativo con el tratamiento de la nueva subjetividad pulsional ${ }^{3}$ nietzscheana, sobre todo en el importante parágrafo 119: «Vivir y fabular. — Por muy lejos que alguien pueda llegar en

3 Decimos subjetividad pulsional porque esas fuerzas que son las pulsiones interpretan el suceso, es decir, se nos presentan como razón poética o creativa: «[...] el que la razón creativa se imagine hoy causas tan diferentes a las de ayer para los mismos estímulos nerviosos: el motivo de esto está en que el souffler [apuntador] de dicha razón era hoy distinto que el de ayer-era otra la pulsión que trataba de satisfacerse, de actuar, de ejercitarse, refrescarse o descargarse, - hoy era ella la que tenía su flujo, ayer era otra» (A 119: 555). 
el conocimiento de sí mismo, nada será, sin embargo, más incompleto que la imagen que se haga del conjunto de las pulsiones que constituyen su ser» (A 119: 554). El cultivo de sí que la obra promueve, como tarea a la vez educativa y terapéutica, se va a concebir como un trabajo individual-cultural sobre las pulsiones, trabajo que nos va a constituir como subjetividad disciplinándolas ${ }^{4}$.

El educador esencial, el filósofo como educador, sería propiamente $t u$ liberador, el liberador tuyo, dedicado a liberarte a ti. Por eso una cosa es el filósofo que nos educa liberándonos, y otra muy diferente el que enseña en las instituciones de enseñanza. La dimensión crítica de las reflexiones educacionales nietzscheanas en Aurora encuentra su motivación profunda en el disgusto del filósofo ante el hecho de que las «preguntas más personales por la verdad» (A 196: 591) no nos permitiría hacerlas, en absoluto, la formación que ahora recibimos. En una consideración subjetiva de la verdad, para la cual, por supuesto, no habría tiempo en la enseñanza institucional, tomada ésta en el sentido de formación cultural, es verdadero lo que viene requerido por las necesidades más personales del individuo (Schmidt 2015: 272). Por eso es desde sus necesidades e intereses como habría que volver a diseñarla, pues la pregunta en cualquier caso esencial le parece ser a Nietzsche la de «qué quiero yo al formarme». Pero lo que a cada cual le interesa, ante todo, es la cuestión «existencial» de cómo y hacia dónde vamos en esta vida de unos setenta años que nos va a corresponder, más o menos, a cada uno. Probablemente, cuando la educación establecida ni siquiera la roza, se comporta inteligente o astutamente, pues ¿de qué le valdría a una tan breve ola saber cómo y adónde va a ir a parar al final? Lo mismo hasta sería peor saberlo. Pero al no plantear este tipo de preguntas, la educación que se nos proporciona se hace incapaz de satisfacernos, de hacernos sentir «orgullosos». Y en ese punto desliza el filósofo la sospecha de que esta falta de orgullo no sería virtud, sino más bien lo contrario (A 196: 591).

A renglón seguido debemos preguntarnos de qué se nos tendría que liberar para que pudiéramos llegar a ser los que somos. Ya sabemos que de eso se trata, para Nietzsche, con una educación que vaya más allá de la mera formación profesional. En Aurora la respuesta salta a los ojos casi desde el comienzo: uno tiene que liberarse de la moralidad de la costumbre. «El concepto de moralidad de la costumbre. - [...] la moralidad no es otra cosa (esto es, nada más) que obediencia a las costumbres, sean estas cuales fueren; y las costumbres son la manera tradicional de valorar y de actuar» (A 9: 493). La moral, durante milenios, la moral histórica y sobre todo prehistórica,

4 En A 109: 545, un parágrafo titulado «Dominio de sí mismo, moderación y su último motivo», Nietzsche nos presenta los métodos o las técnicas tradicionales de dominio de las pulsiones. No sería descabellado pensar que Aurora estaría llamada a superarlos con el ejercicio de la pasión del conocimiento. 
habría sido y en cierta manera sigue siendo hoy, es verdad que en forma más debilitada, moral de la costumbre. O sea, obediencia a la tradición y a los antepasados, y en modo alguno obediencia a una instancia sobrenatural, externa a la sociedad, como tampoco obediencia a la autoridad de la razón. Así que malo, o mejor, malvado, tiene que significar por fuerza lo mismo que individual, inesperado, original, sobre todo en las circunstancias originarias de la sociedad humana, aunque es lícito pensar que, en alguna medida, siempre habría sido así: «El hombre libre es sin moral, puesto que procura depender en todo de sí mismo y no de una tradición» (ibid.). La comunidad habrá de castigarlo, sin duda, aunque no le hará falta esforzarse mucho porque el mismo individuo que se atreve a ser libre o a apartarse de la dictadura de la costumbre sufrirá de mala conciencia, o tendrá conciencia de su maldad ${ }^{5}$.

Toda acción individual, cualquier manera de pensar que sea individual provoca escalofríos; es inimaginable lo que tienen que haber sufrido a lo largo de la historia los espíritus más singulares, escogidos y originales por haber sido considerados siempre malvados [bösen] y peligrosos, es más, por haberse visto ellos mismos así. Cuando es la moralidad de la costumbre la que rige, cualquier tipo de originalidad adquiere conciencia de maldad [A 9: 495].

Dada la cuasi omnipotencia de la moralidad de la costumbre, es forzoso afirmar que al principio todo pertenecía al ámbito moral, pero en primerísimo lugar la educación (Erziehung) (A 9: 494). En las sociedades tradicionales la educación agota su sentido en la integración del individuo en la comunidad y sus costumbres, su meta no es sino esta incorporación. En ellas se trata de que el individuo «educado» se haya convertido en individuo obediente, siervo de su tradición. Nada le importa a la educación tradicional el interés de los individuos. A las costumbres se las obedece porque mandan, no porque manden algo beneficioso para el individuo. Ahora bien, con las figuras de Sócrates y Jesús, iba a surgir la novedad del individuo desviándose de la moralidad de la costumbre. De ahí que en su tiempo ambos fueran considerados malvados, y en consecuencia perseguidos y muertos. Sócrates y Jesús sí que prometían una vida feliz al individuo cumplidor de sus preceptos y reglas. Pero si de ellos conservamos memoria es solo porque, a través de sus seguidores, lograron fundar una nueva tradición, una nueva moral, y por tanto una renovada comunidad histórica (ibid.). Entonces, estaremos de acuerdo en que solo gracias a la personalidad emancipada se puede superar la moral colectiva tradicional en favor del individuo (Schmidt 2015: 88-89), y por

5 Insiste Aspiunza en su edición de la obra ( $c f r$. A 9: 496, nota 145) en la importancia de la diferencia entre schlechtes Gewissen, que es la expresión corriente, y böses Gewissen, que es la que emplea Nietzsche. 
tanto concluiremos que solo en su virtud se haría posible el progreso moral entendido al modo nietzscheano. Es verdad que Nietzsche impugna el sentido casi diríamos que natural del fenómeno educativo en la sociedad más o menos tradicional, que es el de la integración cultural del individuo en su comunidad. Pero, al fomentar la opuesta educación para el individuo, estaría en realidad promoviendo una educación renovada, esto es, el progreso moral.

En segundo lugar, este sentido que Nietzsche asigna en Aurora al proceso educativo se especificará como liberación moral de la moral. Más concretamente, como terapia o aprendizaje de una nueva forma de vida, pero esta vez creativa (Ansell-Pearson \& Bamford 2021). Una forma de vida por supuesto desprendida de los ideales de la moralidad de la costumbre, pero que sería en sí misma moral porque el espíritu que la animará no es sino el de la última moral que les queda a los espíritus libres tras la constatación de la muerte de Dios ${ }^{6}$. Yendo más allá de los cristianos ${ }^{7}$, y desde luego, en contra de los filisteos de la cultura ( $c f r$. Görner 2000: 139-141), esta última moral sería la moral que prohíbe la mentira en el sentido del autoengaño; la moral de la integridad, de la probidad u honestidad intelectual (Redlichkeit).

Es clara la alusión de Nietzsche, en el título de A 13, al último texto publicado por G. E. Lessing en 1780, La educación del género humano (Schmidt 2015: 91). Y es que en esta obra se defiende que la liberación de la tradición es el modo que tiene la inteligencia de desarrollarse. Vimos que las costumbres ancestrales lo han sido todo en lo relativo a la moral, y que cualquier desviación de obra o pensamiento respecto del modo de conducirse socialmente aceptado tuvo y aún tiene que ser experimentado por el individuo como conciencia malvada. Pues bien, para librar del miedo y de la superstición a ese individuo amenazado, exhortará aquí Nietzsche a todos los hombres de buena voluntad a expulsar del mundo la noción de castigo [Straf]. El concepto de castigo pertenecería a un arte de interpretación demencial con el que se ha llevado la tontería y la locura (Tollheit) hasta el punto de hacer sentir a los hombres la existencia misma como castigo: «[...] ¡ es como si hasta ahora hubieran sido fantasías de carceleros y de verdugos lo que ha estado encauzando la educación del género humano!»(A 13: 496). Tiene en cuenta quizás el filósofo la manera terrible que ha tenido de potenciarse esta noción de castigo con el concepto cristiano de pecado. Con la idea del pecado y con la de su castigo consecuente, se atemoriza a los jóvenes, se inhibe su inteligencia y se hace enfermar su voluntad. No en vano apuntaría esta idea al

6 De manera que, en Aurora, no se trata tanto de disparar contra «la» moral, como contra la moralidad de la costumbre.

7 La veracidad en que se nos ha educado era una virtud cristiana. Por eso se trata con todo esto de la aniquilación «cristiana» del Cristianismo, o de la auto-aniquilación «hipermoral» de la moral. Cfr. A Prólogo 4: 487-488. 
flanco más sensible en que la moralidad de la costumbre ha puesto su garra en el alma individual. La nueva educación del género humano habrá de superar el estúpido mecanismo milenario que entiende acción y consecuencia de la acción como falta y castigo, igual que Lessing había cifrado la meta del progreso en hacer el bien por el bien mismo y no por una supuesta recompensa. La guerra contra la idea de castigo la va a enfatizar Nietzsche como decisiva. Para vencer en ella va a ser de gran ayuda la educación científica moderna. Porque en la cultura científica moderna se da cita la pasión del conocimiento con la crítica de los prejuicios morales ${ }^{8}$. Como se sabe, para Nietzsche la ciencia nos conduce necesariamente a esa filosofía según la cual todo es azar y necesidad, y por eso, gracias a la cultura científica, se puede por fin recuperar lo que después denominará el filósofo «inocencia del devenir».

La liberación del miedo resultante de toda desviación de la moral de la costumbre nos la traerá, para empezar, el mismo conocimiento de que el individuo creador, en tanto meta de la educación, tiene que hallarse, en su mismo origen, atormentado por su conciencia malvada. Según la imagen wittgensteiniana, estar encerrado el individuo en su habitación es como estar en compañía de un tigre. De forma que un modo de cumplirse la liberación sería como un liberarse del miedo a la soledad (A 443, A 177). Pues no es el miedo a la soledad más que una consecuencia de la educación tradicional. No solo eso, ese miedo ha venido siendo su refuerzo, su consagración, oficiando además como válvula de seguridad. Por eso, la nueva educación que Nietzsche avizora y pretende promover nos enseñará a soportar la soledad, a dejar de considerarla como un castigo por nuestras ofensas al prójimo: «Sobre la educación. - Poco a poco se me ha ido aclarando cuál es el defecto más general de nuestra forma de enseñar y de educar: nadie aprende, nadie lo pretende, nadie enseña-a soportar la soledad» (A 443: 655). Antes al contrario, sería la soledad el camino que conduce a uno mismo. No es solo educar para ser capaz de soportar la soledad, sin sufrir por estar solos, sin aburrirnos por estar solos, sino también educar de modo que la soledad se convierta en un medio para llegar a ser el que se es:

Estar solo con el juez y vengador de la propia ley es terrible. Así es arrojada una estrella al espacio vacío y al soplo helado de la soledad [...]. Hay sentimientos que quieren matar al solitario; ¡si no lo consiguen, habrán de morir ellos mismos! ¿Pero podrás tú ser un asesino? [...]. ¡Y guárdate de los buenos y los justos! Les gusta crucificar a quienes crean para sí mismos una virtud, —odian al solitario [...]. Solitario, ¡tú andas el camino hacia ti mismo! (Za I, «Del camino del creador»: 108).

8 Reiteremos de paso que el nudo de Aurora, considerada en su conjunto, es el que une pasión del conocimiento y emancipación (de la moralidad de la costumbre). 
El asunto de la soledad nos llevaría directamente al sentido de la educación en Aurora. En efecto, con el objetivo de hacer posible el surgimiento educacional del individuo creador, el cultivo de la soledad es presentado como una medida para defenderse de todo «el ajetreo ensordecedor del mundo actual que nos vuelve estériles, improductivos» (Schmidt 2015: 376). Sería condición de posibilidad, la soledad, de la creación individual, al servirle al humano de aislamiento. La soledad como verdadero antídoto de una vida moderna entregada invariablemente al momento que pasa. Al ambicioso apresurado de la gran ciudad que cree su deber lanzar su opinión sobre todo lo que pasa, «y siempre pasa algo», le advierte Nietzsche que «el hondo silencio de la gestación» no le visitará jamás (A 177: 582).

En tercer lugar, otro resultado positivo de nuestra investigación es la constatación del vínculo entre educación y transvaloración. Podemos de hecho pensar que la Umwertung ya se halla latiendo en Aurora. Nietzsche está señalando ya aquí la importante función educacional que desempeñan algunos de los considerados males o «vicios» desde la perspectiva de la moralidad de la costumbre, tales como la crueldad o el amor propio (A 30, A 397). La aborrecible crueldad humana podría sublimarse, o incluso transfigurarse en virtud, como lo demuestra el modelo griego de la rivalidad entre individuos y ciudades-estado. Viene a concluir Nietzsche que la célebre moral de la distinción es «en el fondo el gusto por una crueldad refinada» (A 30: 506). Ahora bien, este aristocrático afán de distinción, el impulso y el gusto por sobresalir, tendría un rendimiento educativo evidente. En el sentido de que el placer de hacer sufrir al otro, provocándole envidia y haciéndole sentir su propia impotencia con la exhibición de nuestras virtudes, habría fomentado en el mundo antiguo una tensión ética favorecedora de la autosuperación ${ }^{9}$. Y por otra parte, entre los discípulos de un mismo maestro, compitiendo entre ellos por distinguirse ante él por su sabiduría, habría un ingrediente de crueldad refinada que afortunadamente también favorece la autosuperación.

También se compara la educación con la procreación: «Educación. - La educación es la continuación de la reproducción y muchas veces una especie de paliativo de esta» (A 397: 643). Schmidt (2015: 358) cree legítimo deducir que este aforismo en realidad nos estaría remitiendo al amor de sí, ese amor propio que no le puede faltar a ningún buen maestro ${ }^{10}$. Está aquí presente

9 Es una referencia a la positiva visión griega de la envidia, subrayando su rendimiento educativo. Pero aquí el Kommentar nos remite, apoyándose en A 18 y en MBM 229, a Lou Salomé calificando a Nietzsche de sadomasoquista, informándonos además de que la obra de Sade estaba entonces de moda en Alemania (Schmidt 2015: 121). Podemos hasta pensar que, según esta transvaloración concreta, el placer de la crueldad intervendría no solo en el educador sino también en el que está siendo educado, esta vez como placer masoquista.

10 «397: (...) Aquí el punto de vista [de Nietzsche] la contempla [a la educación] por medio del 
la idea estética habitual según la cual educar es algo así como imprimir formas, incluso la forma de la mente del maestro, en la materia amorfa de las mentes juveniles. Por eso justamente educar sería como la continuación de la reproducción, algo así como un modo de referirnos a esta de modo eufemístico, siempre en la línea del embellecimiento o la mejora. Así que el de la enseñanza-aprendizaje casi se llega a concebir como un proceso artístico de base pulsional. No se trataría solo, ni principalmente, de desarrollar los factores cognitivos, sino que en ese proceso habrán de desempeñar un papel esencial los emocionales, particularmente el estado de ánimo, lo que en inglés dicen el mood $^{11}$. En A 397 se apunta además, de nuevo, que el sentido natural de la educación no es otro que el de la adaptación de lo nuevo a lo viejo, la integración de la generación joven en su cultura tradicional. Esto parecería oponerse a todo lo hasta aquí dicho. Pero en realidad no es así, porque hay algo importante, la aparición de un tema venerable en el que, paradójicamente, encuentra Nietzsche la posibilidad innovadora de la educación, lo que esta tendría de inesperado o imprevisible. Si el destinatario de la verdadera educación es el individuo necesitado de orientación vital, en lo que respecta a la función del maestro se van a considerar del mismo modo las capacidades de un individuo concreto. Lo incontrolable y creativo del filósofo como educador radicaría, nada menos, en su afán de una cierta inmortalidad, de inmortalizarse a sí mismo en discípulos y continuadores. Sería el maestro imaginado otra vez aquí como artista, poeta de humanos en proceso de formación. El viejo tema heleno de la educación como continuación de la reproducción, la figura del erótico Sócrates fecundando el alma del joven con la semilla de sabiduría de su bello discurso. Si la única «inmortalidad» del cuerpo es la del cromosoma, la sexualidad como presupuesto de la vida, la que corresponde al «alma» vendría servida en la buena lección de filosofía.

\section{LA FACETA CRÍTICA}

No podía faltar la aplicación de estas ideas a la enseñanza de la época cultural de Nietzsche, bien conocida por él por su experiencia en la enseñanza media y superior. Es natural que sus críticas radicales a este modelo educativo que él mismo sufrió se encuadren en la valoración general de la cultura alemana del momento, una valoración que se sitúa desde luego en una perspectiva

análisis psicológico, llevándola al tema del amor propio (amour propre o amour de soi), predilecto de los moralistas» (Schmidt 2015: 358). Hacer que el otro se alegre es para cualquier persona su mayor alegría, porque al alegrarle se alegran a la vez cincuenta impulsos propios de esa persona (A 422).

11 Recientemente se ha subrayado la importancia de lo emocional en la educación tal y como la tematiza Aurora, pues no en vano la moralidad de la costumbre se habría impuesto al individuo manipulando sus estados de ánimo y sus pasiones (Ansell-Pearson \& Bamford 2021: 58). Lo que Nietzsche propondría es luchar contra ella usando sus mismas armas. 
intempestiva $^{12}$. Pues bien, esta crítica que despliega Nietzsche también en Aurora prolongaría sus conocidos ataques de juventud, por ejemplo cuando mantiene que la universalización de la formación cultural, de la Bildung, trae consigo la trivialización de la cultura. Insistirá otra vez en que la gran mayoría de los jóvenes «son ingresados» en la etapa educativa previa a la Universidad sin hallarse poseídos por ninguna clase de vocación científica o artística. Pero la obligación de esforzarse en la ciencia o en el arte sin ningún hambre de cultura, pronto les conducirá a la indiferencia y al hastío, o incluso a la amargura del que siente desperdiciada su juventud. Los estudiantes, en su mayor parte, ignoran el sentido de los esfuerzos que se les exigen, de forma que se les hacen ímprobos y tediosos. Los centros de formación cultural habrían de ser separados cuidadosamente de los de formación profesional, porque en realidad sus objetivos no son en absoluto comparables. Se confunde a veces la insistencia nietzscheana en esta separación con la retrógrada defensa de una injusta educación elitista, pero para el filósofo sería un hecho incontrovertible que la mayoría de las personas carece de interés real por la dura tarea de la preparación para el conocimiento científico y la creación artística. Es una tarea tan ardua y tiránica, que incluso convierte la genuina vocación de los menos en una maldición para ellos mismos, de la que a veces querrían liberarse hasta los más entusiastas.

Esto ocurre, según Nietzsche, con la enseñanza de las ciencias naturales, pues la educación de su época no transmitiría la pasión por el conocimiento experimental. Pero también sucede en la llamada «educación clásica». Y es que no se puede decir que sea una educación real la educación clásica que se imparte en los centros de enseñanza, puesto que no proporciona, en absoluto, una visión de la vida grecorromana. Lo que se hace, en cambio, es administrar a los estudiantes una cultura meramente formal, con el agravante de que tanto ellos como sus profesores van a acabar estando seguros de que tendrían en sus manos el secreto de la cultura antigua. Pero en absoluto lo tienen, ni siquiera habrían reparado en nuestra radical extrañeza de modernos ante el mundo antiguo. Justamente en este punto se localiza la razón de que valga la pena aprovechar intempestivamente la cultura griega antigua como contraste crítico del presente moderno. Naturalmente, en el Kommentar, este parágrafo A 195 que ahora analizamos se pone en relación con Utilidad y perjuicio de la historia para la vida, ya que está claro que todo su sentido se enhebra en el argumento de la necesidad de practicar otro modo de Historia, el que sirva de ayuda y no de rémora para vivir el presente (Schmidt 2015: 272). Los pensadores helenísticos tienen mucho que aportar, entonces, para enseñarnos

12 Nuestro filósofo habría estado siempre, como rezaba el mismo título del libro que Rudolf Steiner publicara en 1895, en combate contra su tiempo (Steiner 1963). 
la tarea de vivir y el oficio del cuidado de sí mismo. Un pensamiento genuinamente terapéutico el suyo, del que subrayará Aurora su virtualidad poderosamente formativa en el sentido más práctico posible. Un pensamiento este, el del helenismo, que podría ayudar a los modernos a liberarse de las brumas mentales que hacen de la vida actual un infierno de neurosis.

La relevancia educadora de los filósofos helenísticos para nosotros los modernos viene del hecho, para Nietzsche evidente, de que sus terapias filosóficas constituyen una auténtica educación en la realidad. La recuperación que hace Aurora de esta filosofía es un gesto intempestivo, pues la cultura alemana de la época que más habría atraído el interés de los europeos fue la del Clasicismo, el Romanticismo y el Idealismo. La fama que alcanzaría hizo pensar a las otras naciones de Europa que los alemanes (Schiller, Humboldt, Schleiermacher, Hegel, Schelling) habían encontrado por fin la manera de habitar en el cielo, cuando en realidad, como Nietzsche apunta con su característico sarcasmo, se habían limitado a estar en una nube (A 190: 587). La clave del idealismo alemán se halla aquí, para Nietzsche, en la gran impostura de pretender parecer, a toda costa, moralmente motivados, exaltados o impresionados. En el terreno estético, su anhelo insaciable de ver a las cosas bellas, en lugar de verlas como son, nos engaña con la habilidad tan de idealistas de hacer pasar el mal gusto por sublime refinamiento, presuntamente inspirado, encima, en el modelo de la Antigüedad Clásica.

Se trata de un idealismo blando, bonachón, con destellos plateados, que lo que ante todo desea tener son gestos y voces que finjan nobleza, cosa tan pretenciosa como inofensiva, animada por la más cordial aversión hacia la 'fría' y 'seca' realidad, la anatomía, las pasiones absolutas, todo tipo de contención filosófica y escepticismo, pero sobre todo hacia el conocimiento de la naturaleza siempre que no se deje utilizar en pro de algún simbolismo religioso. (ibid.) ${ }^{13}$.

Desde la moral del espíritu libre, la de honestidad intelectual, habría que considerar al idealismo alemán justamente como inmoral, porque es deshonesto, se engaña a sí mismo y engaña a los demás. En las obras de Goethe y de Schopenhauer, gracias a que habrían quedado fuera de la impostura idealista, todavía podía mostrarse la forma del mundo real. Ahora bien, a juicio de Nietzsche esta cultura alemana del delirio idealista ya se habría acabado,

13 El comentarista de A 190 llegará a contextualizar la crítica cultural nietzscheana del idealismo alemán remitiendo al lector a sus precedentes en Heine, en la Junge Deutschland, y en el realismo y el naturalismo europeos de la segunda mitad del XIX. Hasta tal punto que el efecto provocado en este, aparte del reconocimiento de la utilidad de la erudición histórico-crítica, sin duda mayor si se hubiera mantenido aquí en la moderación académica, pudiera ser el de lamentar su efecto disolvente de la originalidad de Nietzsche (Schmidt 2015: 262-263). 
pero para pasar a ser sustituida por algo peor, el delirio político y nacionalista. Y por fin, de nuevo, el sarcasmo del filósofo observaría que, como también esto llama la atención de los extranjeros, los alemanes pueden seguir estando contentos.

\section{EL PROBLEMA FILOSÓFICO DE LA EDUCACIÓN EN AURORA}

Al identificar con claridad la moralidad de la costumbre desde su ya incoado e implícito proyecto transvalorador, Aurora representa un paso de importancia en la filosofía nietzscheana de la educación pues sitúa en el individuo su sentido último. De las dos tendencias dominantes en la época de Nietzsche nos informa Cooper (2010): en los Gymnasien destacaba la idea del conocimiento por el conocimiento, característica de los académicos o Gelehrten proclives a generar filisteos de la cultura semejantes a ellos; mientras que en las llamadas Realschulen se trataba, por el contrario, de convertir a los jóvenes en ciudadanos productivos, útiles a la economía nacional y a la administración del Estado. Es verdad que contamos con declaraciones de Nietzsche atacando a las dos tendencias, pero hay que matizar que no deja de concederles un cierto valor a ambas ${ }^{14}$. Insistirá el filósofo, eso sí, en que en absoluto deben confundirse ni la erudición ni la utilidad con la verdadera educación tal y como habría que entenderla, por mucho que no haya una estricta «definición» nietzscheana de ella, como reconoce el mismo Cooper (2010: 25). A un atisbo del significado nietzscheano de esa educación verdadera podemos llegar reparando en que las dos tendencias educacionales mencionadas, la académica y la utilitaria, aparentemente tan opuestas, en realidad convergen en su fin esencial: forjar ciudadanos comunes y corrientes, como las monedas, que puedan circular sin trabas, en tanto intercambiables, calculables, previsibles. Las dos entienden de idéntica manera el proceso educativo, como homogeneización radical y eliminación de las diferencias. En ambas acecha la misma moralidad de la costumbre, todopoderosa, en la forma de la conformidad con las opiniones y gustos de la sociedad del presente.

Por lo que hemos visto a partir de Aurora, Nietzsche tiene que estar resueltamente en contra de esta pretensión niveladora de la enseñanza de su época, y a favor, en consecuencia, de una verdadera educación: aquella que, si asumimos la interpretación existencialista de Cooper, se propone cultivar individuos auténticos. Pero para no enredarnos en las complicaciones de la Eigentlichkeit heideggeriana, ni tampoco en las del concepto ilustrado de autonomía, tal vez prefiramos la otra propuesta del mismo autor, cuando

14 Hay que tener en cuenta, además, que la alabanza nietzscheana del realismo, que hemos comentado más arriba, nada tendría que ver con el empeño institucional de formar ciudadanos útiles a la economía, al Estado y al ejército. 
atiende difusamente a la aportación foucaultiana. Según ella, la autenticidad, meta última de la verdadera educación, consiste en la apertura del individuo a una preocupación o a un cuidado de sí tanto situacional como proyectivo (Cooper 2010: 20). Solo haciéndose cargo de su situación real, podrá el individuo cuidar de sí mismo y cultivarse teniendo a la vista sus posibilidades futuras. Todo ello para llegar a ser el que es.

Esto nos conduce directamente al problema filosófico central de la educación nietzscheana, tal y como ahora se le vuelve a plantear al filósofo en Aurora, o sea, en relación con su nueva idea de subjetividad. Porque tras despedirnos del sujeto metafísico tampoco tendríamos «individuo» como tal, sino jerárquicas organizaciones transitorias, y escasamente conscientes, de la multiplicidad pulsional que es el cuerpo. Se tiene que plantear entonces la cuestión de cómo entender el cultivo de las pulsiones, como auto-cultivo, y el trabajo de subjetivación operado por las culturas y sus correspondientes códigos morales (A 109). Habrá que pensar la educación desde Aurora como un complejo proceso de (re)subjetivación liberadora, un proceso en buena parte inconsciente que por tanto no dependería más que muy parcialmente de nuestras intenciones. La pregunta ya la vimos al comienzo, si bien formulada de otra manera muy distinta, en relación con el conocimiento trágico: ¿cómo pensar la posibilidad de la educación si excluimos la presunta libertad de la voluntad de un sujeto metafísico? (A 128). «Nietzsche explica que el presuntuoso deseo de ser enteramente nuestros propios autores tiene sus raíces psicológicas en el deseo, básicamente narcisista, de experimentarnos a nosotros mismos como todopoderosos» (Ansell-Pearson \& Bamford 2021: 149).

La ya mencionada observación de Brusotti nos pondría en la pista válida para abordar el problema: «Es escribiendo como Nietzsche quiere dar figura a su propio camino de vida hasta convertirlo en una totalidad estética» (1997: 202). El filósofo habría podido llegar a ser el que era solo de un modo: escribiendo, esto es, escribiendo al dictado inconsciente de una misión que era solo suya, la suya. Recupera Brusotti un fragmento póstumo de la época de preparación de Aurora, en el que el filósofo se dirige a sí mismo, y a todos los que van a ser educados por él, este crucial imperativo: «Llega a ser, sin parar, el que eres-imaestro educador y escultor de ti mismo» (FP II 824 11 [297]). Nietzsche confiesa aquí que él no sería propiamente un escritor, porque no escribe para otros sino solo para sí mismo. Si escribe sin cesar es, ¡nada más!, para conservar en el recuerdo sus «buenos momentos», y poder encontrar así la conexión entre ellos, su enlace, es decir, la «cadena de oro» de(l) sí mismo. Escribiendo, y no dejando jamás de escribir, va llegando el filósofo a ser el que es, quizás cualquier filósofo. La educación verdadera, que en sí misma no sería institucional, ni erudita ni práctica, es la educación en y 
por la propia escritura. Una escritura pulsional que hay que entender según el lema de mihi ipsi scripsi. En suma, verdadera técnica del yo, técnica escritural de subjetivización, camino para llegar a ser el que se es. Y es que al escribir sucedería como si las pulsiones se equilibraran recíprocamente, llegaran entre ellas a una especie de pacto. Y por eso la escritura sería el modo privilegiado de hacérselas conscientes a uno mismo, o lo que es lo mismo, la más eficaz manera de impartir justicia (GC 333: 851), de acceder a la objetividad entendida a la manera nietzscheana (GM III, 12: 529-530). Es decir, de conquistar la subjetivación en la objetividad. A fuerza de escribir emergería un cierto «sujeto», lo que significa algo o alguien dotado de una relativa coherencia momentánea entre múltiples perspectivas diferentes. Aurora es un verdadero proyecto educativo porque está escrito para proporcionarle al lector los necesarios recursos intelectuales, emocionales y estratégicos para liberarse de la moralidad de la costumbre y así poder llegar a ser el que es. Sobre todo, por la escritura, y con la escritura nietzscheana como modelo: Nietzsche como educador.

\section{REFERENCIAS BIBLIOGRÁFICAS:}

ANSELL-PEARSON, K. y BAMFORD, R. (2021), Nietzsche's Dawn. Philosophy, Ethics, and the Passion of Knowledge. Hoboken: Willey-Blackwell. Archivo Kindle.

BRUSOTTI, M. (1997), «Erkenntnis als Passion. Nietzsches Denkweg zwischen Morgenröthe und der Fröhlichen Wissenschaft». Nietzsche Studien, 26, 1. 199225.

COOPER, D. E. (2010), Authenticity and Learning: Nietzsche's Educational Philosophy. London and New York: Routledge and Kegan Paul, 1983. Archivo Kindle.

DUMONTEIL, J. (2015), Nietzsche et l'éducation: À l'école de l'Antiquité. Paris: L'Harmattan. Archivo Kindle.

GÖRNER, R. (2000), Nietzsches Kunst. Annäherung an einen Denkartisten. Frankfurt a. M.: Insel Verlag.

MARTON, S. (2021), Les ambivalences de Nietzsche. Types, images et figures féminines. Paris: Editions de la Sorbonne.

NIETZSCHE, F. (2007), Correspondencia II. Madrid: Trotta.

NIETZSCHE, F. (2007), Fragmentos póstumos I. Madrid: Tecnos.

NIETZSCHE, F. (2008), Fragmentos póstumos II. Madrid: Tecnos.

NIETZSCHE, F. (2006), Fragmentos póstumos IV. Madrid: Tecnos.

NIETZSCHE, F. (2014), Obras Completas III. Madrid: Tecnos.

NIETZSCHE, F. (2016), Obras Completas IV. Madrid: Tecnos.

SÁNCHEZ MECA, D. (2018), El itinerario intelectual de Nietzsche. Madrid: Tecnos.

SCHMIDT, J. (2015), Kommentar zu Nietzsches Morgenröthe. Historischer und kritischer Kommentar zu Friedrich Nietzsches Werken. Herausgegeben von der 
Heidelberger Akademie der Wissenschaften. Band 3/1. Berlin/Boston: Walter de Gruyter.

STEINER, R. (1963), Friedrich Nietzsche. Ein Kämpfer gegen seine Zeit. Dornach: Verlag der Rudolf Steiner-Nachlassverwaltung. 